No. 10,2020

\author{
http://www.journalssystem.com/pno/
}

\title{
Analysis and Short Presentation of Study on Motivational Salience and Satisfaction with Training in the Field of Security and Defence
}

\section{Original article}

Accepted: 11 November 2020

Published: 14 December 2020

\section{Peer review:}

Double blind

Keywords:

motivational salience of military students, satisfaction with training, military training, professional preparation of cadets

This work is licensed under the Creative Commons AttributionNonCommercial-NoDerivatives 4.0 License

\author{
Elitsa Petrova, Assoc. Prof. Sc. D ${ }^{1}$ \\ ORCID (D)0000-0002-8291-7108
}

\author{
Vasil Levski National Military University, Bulgaria \\ Blvd. 76, 5000 Industrial zone,Veliko Tarnovo, \\ Bulgaria
}

\begin{abstract}
Purpose: The purpose of the article is a presentation and an analysis of research on motivational salience and satisfaction with training in the field of security and defense that was carried out with the assistance of a number of universities and academies in Europe.

Method: Survey research and statistical analysis including, and certain statistical methods were applied for processing of the grouped statistical data, their interpretation and offering of the relevant decisions.

Results: The study attempts to outline the foundation of the methodology for conducting research on motivational salience and its relation with satisfaction in security and defense training, following the example of higher education institutions in Europe. The research findings are characterized by the scale of scientific and practical research and covering 19 educational institutions in the field of security and defense in Europe. The research is distinguished by the presence of a scientific subject not only at the national level but also at the international level. The results are in the area of interest to the academic staff of the military universities and academies of Austria, Belgium, Bulgaria, Estonia, Spain, Lithuania, Poland, Portugal, Romania, Slovakia, the Netherlands, the Czech Republic, Sweden, Switzerland, and others.

Conlusion/findings: The study was discussed at the extended scientific board of the Logistics of the Security Department at the Vasil Levski National Military University in Bulgaria. The thesis that has been elaborated as a result of carried out works was the subject of the defense in the Security and Defence area of higher education in Bulgaria.
\end{abstract}

\footnotetext{
1 Elitsa Petrova is Associate Professor in the field of "Social, Economic and Legal Sciences", Doctor in Economics and Management and Doctor of Science in Security and Defense. She is a lecturer at the Vasil Levski National Military University, Bulgaria. She is an author of over 150 scientific publication. She is a member of scientific boards and a reviewer of over 20 journals and conferences. E-mail: elitsasd@abv.bg.
} 


\section{Introduction}

This article presents an analysis of study on motivational salience and satisfaction with training in the field of security and defence trying to acquaint the scientific audience with important scientific research carried out with the assistance of a number of universities and academies in the field of security and defense in Europe. The study is discussed at the extended scientific board of the Logistics of Security Department at the Vasil Levski National Military University in Bulgaria, and its aim, namely - a defence the thesis in the Security and Defence area of higher education, National Security professional field, Organisation and management outside the sphere of material production (National Security) scientific specialty is achived.

The results of very broad research were acomplished in the form of thesis. The thesis consists of an introduction, four chapters, a conclusion, a bibliography of the literature used (312 titles, 185 in Latin and 60 in Cyrillic, 25 laws and normative documents, 42 electronic sources). The 435 pages of the dissertation work contains a cover page, an introduction - 10 pages, the main author's text presented in a volume of 399 pages, a conclusion - 9 pages, and literature - 16 pages. The main text contains 312 figures and 93 tables. The author is Associate Professor at the Logistics of Security Department at the Vasil Levski National Military University in Veliko Tarnovo, Bulgaria.

The study attempts to outline the foundation of the methodology for conducting research on motivational salience and its relation with satisfaction in security and defense training, following the example of higher education institutions in Europe. The results of such studies can be used to build a program-specific program that is directly responsive to its needs. The implementation of such a program can be expected to improve motivation for training, raise motivated individual and collective performance, active professional behaviour, improving the technical and management capacity of the system, applying results to other target groups and sectors for institutional sustainability in the field of education here in the future.

\section{The organization like organized group united around certain goals.}

The organization is not just a mechanical ensemble of individuals, but an organized group united around certain goals. Regardless of the complexity and the strength of the connections between the people in the organization, they are above all independent individuals who do their work in different ways and are led by different motives. Every human individual is an organic system in which genetic and social factors interact and its behavior is the result of this interaction. In each individual, this interaction is different in their specific manifestations and this leads to individual differences and, ultimately, to the uniqueness of each individual. Once they have arisen, organizations are 
constantly changing and following a certain path of development under the influence of numerous external and internal factors. The problem of changes in organizations is particularly relevant in our dynamically evolving security environment and at the same time quite complex. This complexity stems from the fact that major changes occur in all social, economic, political processes and directly and indirectly affect the external and internal environment of the organization. To survive, the organization must be able to change and changes in the environment. For this reason, change is not only one of the most important processes but sometimes the only option for survival.

Various components of organizational culture are subject of scientific research. Atanasova-Krasteva and Ştefănescu look at change-oriented leadership (Ştefănescu R., 2008) the importance of power and the key presence in leadership (Ştefănescu R., 2010), as well as leadership building (Atanasova Krasteva, N., 2011) and leadership establisment of cadets (Atanasova Krasteva, N., 2012). Doncheva writes on a new way of thinking about training and educating trainees (Doncheva J., 2017) while Stoyanova focuses on managing groups (Stoyanova, Stela, 2013) and working with specific groups, including those at risu (Stoyanova, Stela, 2013). Yankov and Ivanov focus on analysing the preparation of intelligence teams for the participation of crisis response operations (Yankov, Y., Ivanov, M., 2018), which correlates with Neshev, Ivanov providing in their own way guidelines for the training of cadets for activities in specific conditions (Neshev I., Ivanov M., 2018). Stoykov and Marinov's approach to training and education in the sphere of security and defense (Stoykov, S., Marinov, R., 2018) as well as several important Stoykov's developments in the field of security and defence (Stoykov, S., 2018) are also of major scientific interest. Kirova, Nedyalkov, Pencheva, Yordanova emphasize that the development of knowledge and skills are under the influence of a crisis in the personal system of values, and the relationship between real life and education is greatly reduced (Kirova, Nedyalkov, Pencheva, Yordanova, 2018) while Świerszcz (Świerszcz, K., 2016) and Ćwik (Ćwik B., 2017) consider national security in modern times in terms of subjective and axiological challenges and build the concept of the threats to security in logistics systems. Procházka and Chalupová point out the special importance of the human factor and military organizational culture in the formation of national strategy papers on defence issues of the country (Procházka, J, I Chalupová, 2017).

At the same time, we cannot miss the adequacy of the statistical processing of information that is extremely important for the conduct of each experiment and the specific processing of the data to obtain true results. For this purpose, we have studied and used the Lectures on Statistical Methods in Psychology (Tsvetkov, D., 2015) and Statistical Methods in Psychology (Tsvetkov, D., 2008) by Tsvetkov, D., which we recommend in the processing of data from social, economic, and psychological research. 
The world hides both great opportunities and great dangers. This naturally leads to behaviors where people are vigilant and active where they constantly explore the environment around them and seek information about their survival and security. Scientific literature often presents the process of change with two metaphors - the "calm water" metaphor and the "rapid water" metaphor. The "calm water" metaphor links the organization of a large ship and the development of - a predictable trip to a calm sea and sometimes a storm. To the contrary metaphor "rapid water" describes the organization as a group of strangers, gathered on a small raft, and its development, such as navigating in a continuous whirlpool and passing through an unknown river. Until recently metaphor for calm waters dominated in the thinking of practicing managers and academics. Given the chaotic changes in the security and defense sphere and the process of globalization, this metaphor is obsolete. Rapid water metaphor reflects the uncertain and dynamic contemporary environment.

Interference in the status quo is not accidental and temporary. Too many things change too fast. Organizations are constantly changing and the need for a global change in the societies we live in is not only obvious but also mandatory. Prosperous organizations never "stop" but are in a continuous process of development. Making change is inevitable, so it is necessary to look for effective ways to manage organizational change. In order to succeed, change must engage and change people's perceptions and behavior.

\section{Motivational salience and satisfaction with training in the field of security and defense}

The presented work "Motivational salience and satisfaction with training in the field of security and defense, following the example of higher education institutions in Europe" justifies the research findings, characterized by the scale of scientific and practical research and covering 19 educational institutions in the field of security and defense in Europe, and we should emphasize the special importance of the expert opinion of Major-General Vasile Roman. The research is distinguished by the presence of a scientific subject not only at the national level but also at the international level. The development is of interest to the academic staff of the military universities and academies of Austria, Belgium, Bulgaria, Estonia, Spain, Lithuania, Poland, Portugal, Romania, Slovakia, the Netherlands, the Czech Republic, Sweden, Switzerland.

The empirical study complies with the requirements of the statistical science of conducting research of this type. During the empirical study a mass of the general statistical population was established, the general statistical characteristics were revealed in the form of dimensions or studied directions, a practice orientated empirical study was done, statistical observation was done, grouping of statistical data were carried out, statistical analysis of the real environment data from the survey respondents were carried out, conclusions and 
conclusions were drawn. The results obtained have an undeniable level of reliability and credibility as they meet the criteria for objectivity, reliability and validity, namely:

- they are not dependent on the person who committed them;

- the answers ensure the unambiguous results, without the possibility of double interpretation;

- there is a relation between the measurement result and the measurement phenomenon;

- a systematic and scientifically based process of gathering information about the individual units was performed on the essential features of the studied set of the statistical population;

- the wording of the questions in the questionnaires used;

- statistical estimates and conclusions based on observations of multiple cases have been prepared.

A representative array of units of the general population is formed, which satisfactorily represent it and the characteristics obtained from it may be taken as estimates of the parameters of the general population. A comprehensive statistical study has been used to cover an array of units through which a phenomenon occurs that is ongoing over the course of five consecutive academic years, including the diagnostic phase of the study. The stages of statistical observation related to the recording of primary data for individual statistical units have been complied with. The survey is specially organized, systematic and scientifically substantiated for the purposes of the survey and was conducted using a set of research methods, the main one being a periodic questionnaire. A categorical grouping of results was performed by forming groups based on certain grouping traits, assigning the corresponding units to the respective groups and examining the units belonging to the respective group. The grouping of units during is done.

In the statistical analysis, certain statistical methods were applied for processing of the grouped statistical data, their interpretation and offering of the relevant decisions. The use of descriptive analysis is characterized by laws based on derived statistical quantities; using diagnostic analysis reveals the reasons for the variation of units of the meaning of a sign; Forecasting for a certain time horizon is made by prognostic analysis.

The established scientific research is proven. The research tasks are solved. The research goes through the necessary research stages of research of a similar type. It was made a methodology for conducting research on the motivational salience and satisfaction with training in the field of security and defense in the example of higher education institutions in Europe.

First part: "Genesis and development of research on motivational salience through the prism of human cognitive activity and its importance for national and international security" solves first, second and third research tasks, namely: first, analyzing the essence of motivational salience and clarified its significance 
in the context of national and international security, as a prerequisite for successful education and training; secondly, the process of initiation and development of motivational manifestation through the prism of human cognitive activity was revealed, as a scientific construct with practical application importance and the link between motivated human behavior with an emphasis on activity satisfaction enriches and broadens the tools for studying motivation and motivational salience according to the specifics of the subject and the object of research and third it was proposed a scientifically based methodology for conducting an empirical study on motivational salience in the learning process and its relation to the satisfaction of the training according to the specifics of the object and the subject of the study.

Motivational salience is a practically oriented construction that is used to explain and describe the already formed human behavior and reveals the cause of the actions of the individual or group of individuals that consists of two fundamental components having a stimulating or repellent effect on the behavior of the individual. Motivational salience is determined by both the negative and positive reinforcements, as well as the individual's past experience, the background of the situation, a number of innate and learned needs, the individual perception of the environment, the individual the self-perception and the self-esteem that the individual has, the social interaction of the individual with other individuals and his situation in the social context, social learning through observation, imitation and modeling, a number of physiological features and numerous psychological characteristics. Motivational salience resultes in satisfaction activities or aspects of operations mainly in two directions: on the one hand reveals favorable impact on satisfaction over the success of the implementation of the activity, productivity and activity of the individual, ie on the whole motivational salience and, on the other hand, dissatisfaction is expressed as a predictor of the occurrence of negative behavioral manifestations.

The enlargement of bilateral and regional partnerships in various dimensions is a factor contributing to the stabilization and full integration of the Euro-Atlantic and European space. In the process of achieving collective security, it should be recognized that human resources are the most valuable capital of the armed forces and investing in people should be seen as an investment in the future with multiple returns. Encouraging and motivating young people to continue their security and defense education is of particular importance for the military-educational system, which develops based on Bulgarian military traditions, in accordance with national and European legislation and in accordance with NATO requirements. From this point of view, we accept motivational salience as an imperative for successful training and education in the context of national and international security.

Second part: "Experimental study on motivational salience in the learning process and its relationship with satisfaction using the example of students at the Vasil Levski National Military University in Veliko Tarnovo, Bulgaria" solves 
the fourth research task, namely: an empirical study was conducted on the motivational performance of trainees in the professional field "Military Affairs", in "Organization and management of military formations at the tactical level" at the Vasil Levski National Military University, analyzes the results of the empirical study, identifies major problem areas, identifies possible solutions and formulates recommendations for improving the motivational expression of trainees, by proposing activities and activities to improve it.

The analysis of the data from the conducted experimental study on the motivational expression in the training process and its connection with the satisfaction of the example of the learners at the National Military University in Veliko Tarnovo, Bulgaria shows:

- reducing the level of personal involvement of learners during seminars and exercises and initiating out-of-class activities to develop personal qualities and skills;

- increasing consensus with the statement that the study of specialized subjects is an important stage in the professional development of learners;

- there is a strong positive impact of military organizational culture, incl. values, norms, symbols, rules and traditions influence the individual performance of learners;

- reducing agreement to the claim that the strictness of the program at the academy / university affects the academic achievement of learners; - reducing the belief that the success of training and presenting learners during the course of study is related to their future professional performance;

- a sharply increasing disagreement with the use of collective punishment; increasing consent to the claim that coercive measures adversely affect motivational expression, and positive reinforcements in the form of material or moral rewards and incentives have a positive effect on motivational expression;

- reducing satisfaction with the choice of academic specialty and military specialization;

- reduction of consent with the claim that the results obtained are directly related to the efforts made.

Third part: "Experimental study on motivational salience in the learning process and its relationship with satisfaction with the participation of control groups following the example of learners at the Vasil Levski National Military University in Veliko Tarnovo, Bulgaria" solves the fifth scientific research task, namely: an experimental study was carried out on motivational salience in the training process and its relationship with the satisfaction with the participation of control groups for comparison of the example of learners at the Vasil Levski National Military University, Bulgaria. 
The empirical study carried out in Chapter Three found that the responses did not depend on the division of the target group of civilian students and cadets, and there were no significant differences in responses between civilian first-time cadets and the first-year students. There were no significant differences in the responses between the control groups and the studied learners'groups. They were found significant differences between the responses of grade levels cadets 2013/2014, $2014 / 2015,2015 / 2016$ and the answers of respondents from the last academic year studied, namely the class of 2016/2017.

Several important conclusions have been made. First. The military organizational culture has a very strong influence, declared as highly positive, both for military students and for civilian students, taking into account all students of National Military University. It is the foundation that builds the individual as a person. Second. There is a tendency to reduce the level of motivational salience over the years, declared by the answers of respondents. Third. A critical point of observation is not the difference between the heterogeneous groups of learners identified as civilian students and students, and the time distribution. Particularly negative trends are emerging in the last studied academic year.

Part four presents a study on motivational salience and satisfaction with training in the field of security and defense with the inclusion of some higher education institutions in Europe, which addresses sixth and seventh research tasks. The analysis of the results obtained from the experimental study on the motivational expression in chapter four in the training process and its relationship with the satisfaction of the example of learners from the National Military University, established:

1. Satisfaction with the choice of academic specialty and military specialization is significant.

2. It is convinced that military / civil training at the university prepares learners for future / military or civilian / leaders.

3. The positive influence of the military organizational culture is determined by the individual motivational manifestation.

4. Experts report a positive impact on university discipline while students have a diminishing impact on their academic performance.

5. The relationship success of training and presenting learners during the training course or results obtained - the effort made is not recognized by the learners. Experts, however, believe that there is such a dependency, and the learning outcomes reflect the intellectual effort that learners make.

6. Used negative reinforcements and used awards and incentives are reflected in a high degree on the motivational salience, which is demonstrated by the respondents.

7. The time spent for general and special military / civic training is determined to be insufficient according to the trainees. According to 
$85 \%$ of the experts, the total satisfaction of the students in the hours allocated for general military training and the hours allocated to the specialized disciplines is high and very high.

The main problems encountered by learners, which prevent them from being as good as possible in the training process, are: insufficient hours spent on general military training and lessons devoted to specialized subjects, more practical classes and practical experience, lack of modern material the techniques and technologies used in the training should be modernized, lack of innovation in the teaching material taught and the teaching methods used, problems in the general human relations between teachers, etc.

Analysis of the results obtained from experimental study on motivational salience of student satisfaction and learning in European educational institutions in the field of security and defense based on available expertise established that the main problems that experts meet in academic practice when working with trainees mainly: poor preparation of students of secondary education, outdated equipment, lack of personal motivation and interest in learning difficulties update lysis of the academic plan and programs, difficulties posed by the lack of secured financial, lack of time for research. As opportunities to increase academic achievement of students are considered to be reporting and the support of the individual contribution, the competitive basis of training and teaching, the improvement of the quality of the training, the renovation of the material base, more practice in a real environment, the refinement of the disciplines studied, the observance and preservation of the main components of the military organizational culture, in various forms of international, collaborative research, projects, forums and others.

\section{Conclusions}

Managing motivational salience requires both an individual and organizational approach. The effective management of multiple individual transitions and the synchronization of individual changes that take place in individuals transform the change from an individual change into an organizational change, which is not only communication and training, but also a process of managing knowledge, experience and competence, interpreted as logical transition from finding a problem to solving it competently. Building cooperation, through the creation and development of networks of security and defense education institutions in Europe, will lead to increased diffusion of knowledge and innovation and will create favorable conditions for the exchange of thoughts and ideas, for the development, implementation and implementation of technologies and research and development through the combined efforts of scientific, research and educational institutions, high-tech enterprises, private entrepreneurs and investors, the state and local authorities. 


\section{References}

Atanasova-Krasteva, N., Leadership Establisment of Cadets, Publishing complex of Vasil Levski National Military University, Veliko Tarnovo, 2012.

Atanasova-Krasteva, N., Some Theories and Views on Leadership, Annual University Conference National Military University, Publishing complex of Vasil Levski National Military University, Veliko Tarnovo, 2011.

Ćwik, B. (2019). Systemic Perception of the Environment of a Modern Organisation. In K. S. Soliman (Ed.), Proceedings of 34th International Business Information Management Association Conference (IBIMA 2019). Madrid, Spain: INT BUSINESS INFORMATION MANAGEMENT ASSOC-IBIMA.

Doncheva J., Principles of training in line with the new thinking and action, SEA - Conf., 3 International Conference, Naval Academy, Constanta, 2017, No 3, pp. 74, ISSN 2457-144X.

Kirova, M., Nedyalkov, A., Pencheva, M., Yordanova, D., University as Prerequisite for Sustainable Regional Development in International Context. IN: Proceedings of the 18th International Scientific Conference Globalization and Its Socio-Economic Consequences, University of Zilina, Slovak Republic, 10-11 October 2018, pp. 2578-2585, ISSN 24540943.

Neshev I., Ivanov M., Some guidelines in the training of cadets for work in mountain conditions, VI int. scient. and techn. conference ENGENERING, TECHNOLOGY, EDUCATION, SECURITY, vol. 1, 2018, Veliko Tarnovo, ISSN 2535-0315.

Procházka, J, I Chalupová, The Czech Republic Defence Strategies: a Comparative Analysis and Qulitative Assessment, International Scientific Conference Strategies XXI The Complex and Dynamic Nature of the Security Environment, Editura Universităţii Naţionale de Apărare „Carol I” 2017, pp. 242-252, ISSN: 2285-8318.

Ştefănescu R., Change oriented leadership, Revew of General Management, issue no.1, edited by Spiru Haret University, Faculty of Management, Brasov, Romania, 2008, ISSN 1841 -818X.

Ştefănescu R., Power and its key role in leadership, Metalurgia International Review, special issue no.4, Scientifing Editing house F.M.R., Bucharest, Romania, 2010, ISSN 1582-2214.

Stoyanova, Stela, Group Management, University Publishing House St. Cyril and Methodius, VT, 2013.

Stoyanova, Stela, Groups - Dynamics and Risks, Publisher: A \& B, VT, 2013.

Stoykov, S., Marinov, R., A comprehensive approach to education and management in the system of security, International conference Knowledge-based organization-Land Forces Academy, "Nicolae 
Balcescu", Volume 24: Issue 1, p.p. 329-334, Sibiu-Romania, 2018, ISSN 1843-682X.

Stoykov, S., Scientific knowledge - source of a competitive advantage in security, International conference on High Technology for Sustainable Development HiTECH 2018, ISBN: 978-1-5386-7039-2.

Świerszcz, K., Bezpieczeństwo państwa w czasach współczesnych w ujęciu podmiotowo-aksjologicznych wyzwań, Przegląd Nauk o Obronności, WAT, nr 1-2/2016, pp.65-82.

Tsvetkov, D., Lectures on Statistical Methods in Psychology, IVIS, Veliko Tarnovo, 2015, ISBN 978-619-205-003-0.

Tsvetkov, D., Statistical Methods in Psychology, Collection of Reports -May Readings, Publisher: Union of Bulgarian Scientists, Veliko Tarnovo, 2008.

Yankov, Y., Ivanov, M., Analyzing the preparation of intelligence teams with the people of the Bulgarian Armed Forces in the case of crisis response operations, VI int. scient. and techn. conference ENGENERING, TECHNOLOGY, EDUCATION, SECURITY, vol. 1, 2018, Veliko Tarnovo, ISSN 2535-0315. 